\title{
क्षे \\ Lavoisier e a sistematização da nomenclatura química
}

\author{
Regina Simplício Carvalho
}

\begin{abstract}
茴
RESUMO

Lavoisier sistematizou a nomenclatura química com base na Lógica de Condillac, e ambos os autores foram inspirados por John Locke. Atacou persistentemente a teoria flogística até a sua derrocada e conseguiu a adesão de vários cientistas a sua teoria do oxigênio. $\mathrm{O}$ uso da nova nomenclatura química implicava a aceitação dessa última teoria. Escreveu várias obras, entre elas Méthode de nomenclature chimique e Traitéélémentaire de chimie, nas quais divulgou a nova nomenclatura química por toda a Europa. Assumindo que a ciência é um produto cultural, tecemos considerações a luz do pensamento de Thomas Kuhn e Ludwik Fleck.
\end{abstract}

PalaVras-Ghave $\bullet$ Lavoisier. Nomenclatura química. Teoria do oxigênio. Linguagem. Kuhn. Fleck.

\section{INTRODUÇÃO}

Lavoisier é comumente relacionado com o surgimento da química enquanto ciência. Além das suas contribuições no âmbito experimental, consideramos como seu grande legado a sistematização da nomenclatura química no final do século xvıII. A questão da linguagem na química é primordial e essencial à prática científica e tanto serve para 0 registro das experiências dos próprios químicos, quanto para a construção do discurso interno do pesquisador, além de meio de comunicação entre os pares e, em casos de divulgação científica, com o público em geral.

Neste artigo abordaremos o desenvolvimento da linguagem química até a época de Lavoisier, ou seja, circunstanciando os pensamentos vigentes e crenças do final do século XvIII, e posteriormente faremos uma breve discussão sobre as duas principais obras de Lavoisier, nas quais foi utilizada a nova nomenclatura química, tecendo as considerações finais à luz dos pensamentos de Thomas Kuhn (2006, 2009 [1962]) e Ludwik Fleck (2010 [1935]), autores que enfatizaram o papel da cultura no processo de construção do conhecimento científico (cf. Condé, 2006). 


\section{A linguagem química}

No século xvIII, a linguagem química existente ainda possuía forte conotação alquímica. As substâncias eram identificadas por nomes arbitrários, ora representando as suas qualidades, ora derivados de termos astrológicos, ora nome de pessoas, ora de lugares. Era comum a existência de dez a quinze nomes diferentes para designar uma determinada substância química. A linguagem dos químicos continha uma multiplicidade de nomes empíricos e tradicionais, tais como "fígado de antimônio", "manteiga de arsênio", "safrão de Marte", "flor de bismuto", "sal da sabedoria" etc. (cf. Santos, 1998). Havia alguma sistematização e certas propriedades comuns aos materiais permitiam estabelecer grupos ou classes de substâncias, tais como cais, piritas e vitríolos (cf. Maar, 1999).

Diferentemente dos objetivos da ciência, a linguagem alquímica era simbólica, figurativa e variável, com o propósito de dificultar a comunicação e o entendimento. A compreensão da linguagem alquímica era restrita aos iniciados, garantindo o caráter hermético e oculto do conhecimento. Para os alquimistas, o conhecimento não deveria ser revelado a todos, e quem o detinha possuiria poder. A natureza alquímica era representada como uma rede de relações por meio das quais o microcosmo sofria influência do macrocosmo (universo). A alquimia tinha um caráter dual: de um lado, era empírica e, de outro lado, profundamente mística. $\mathrm{O}$ alquimista buscava o seu aperfeiçoamento pessoal, além da transformação dos metais em ouro. A alquimia não é considerada ciência, mas um conhecimento da natureza combinado com processos psicológicos de auto-conhecimento (cf. Moran, 2000).

\begin{tabular}{|c|c|c|}
\hline$\odot$ ouro [Sol] & 4 enxofre & H sal amoníaco \\
\hline P prata [Lua] & $\ominus \mathrm{sal}$ & $\Omega$ sublimação \\
\hline Q cobre [Venus] & $\nabla$ água & $\not \not$ mercúrio sublimado \\
\hline$\sigma^{\prime}$ ferro [Marte] & $\triangle$ fogo & $\widehat{\Upsilon}$ realgar (sulfureto de arsênio) \\
\hline$\Varangle$ mercúrio & $\nabla$ água forte & $\left(\begin{array}{c}\text { sais de sulfatos } \\
\text {. }\end{array}\right.$ \\
\hline 5 chumbo [Saturno] & $\nabla$ terra & $\sigma$ retorta \\
\hline 4 estanho [Júpiter] & $\triangle$ ar & $\square$ sal comum \\
\hline
\end{tabular}


As Tabelas 1 e 2 apresentam a simbologia alquímica utilizada tanto para nomear as substâncias conhecidas como para denominar os procedimentos alquímicos utilizados. Os metais eram designados pelos nomes e símbolos dos planetas e os procedimentos laboratoriais relacionavam-se com os símbolos do zodíaco, demonstração inequívoca da influência da astrologia.

Como a comunicação entre os alquimistas e, mais ainda, entre estes e os não alquimistas, era extremamente restrita, a dificuldade quanto à acessibilidade dos textos era imensa. Somente no final do século xvi foi publicado em latim o Alchemia, considerado como o primeiro livro didático de química, escrito em 1597 pelo médico e poeta alemão Andreas Libavius (cf. Moran, 2000). Libavius criticava as ambiguidades da linguagem utilizada, destacando que o alquimista tinha também responsabilidade perante a sociedade. Outra dificuldade presente era de que vários nomes podiam representar uma única substância, assim como uma única substância possuía vários nomes. Para Robert Boyle, o conhecimento não existia como propriedade de um indivíduo, mas sim como propriedade de uma comunidade, e era notória a sua preocupação com a comunicabilidade e a reprodutibilidade de seus experimentos. A descrição do experimento deveria ser a mais fiel possível, para permitir que qualquer outro pudesse reproduzi-lo (cf. Shapin \& Schaffer, 2005).

\begin{tabular}{|c|c|}
\hline 1 Calcinação & $\Upsilon$ Áries \\
\hline 2 Congelação & ð Touro \\
\hline 3 Fixação & П Gêmeos \\
\hline 4. Solução & C Câncer \\
\hline 5 Digestão & § Leão \\
\hline 6 Destilação & ml Virgem \\
\hline 7 Sublimação & $\underline{\Omega}$ Libra \\
\hline 8 Separação & m Escorpião \\
\hline 9 Enceração & $x$ Sagitário \\
\hline 10 Fermentação & $\zeta$ Capricórnio \\
\hline 11 Multiplicação & ఓ Aquário \\
\hline 12 Projeção & ) Peixes \\
\hline
\end{tabular}


Christopher Glaser (farmacêutico e demonstrador do Jardin du Roy), em seu tratado de química de 1677, também criticava a multiplicidade dos nomes das substâncias. Torbern Olof Bergman, em sua obra Oppuscula physica et chemica, alertava que os nomes das substâncias não deveriam ter um significado amplo, mas que elas deveriam ser denominadas de acordo com a verdade. Cada ácido deveria ter um nome distinto, e este refletir-se no nome do sal correspondente. Recomendava também o uso do latim (cf. Santos, 1998; Moran, 2000; Fontes da Costa, 2002). Macquer, por sua vez, recomendava a utilização do nome acide vitriolique em substituição a huile de vitriol, e a inclusão, sob o nome geral de vitriol, de todos os sais vitriólicos (cf. Santos, 1988).

\section{MÉTodo}

Guyton de Morveau, químico encarregado de dirigir os dicionários de química da Encyclopédie méthodique, empreendeu em 1782, em uma reforma da nomenclatura (cf. Bensaude-Vincent \& Stengers, 2001). Os enciclopedistas acreditavam que a difusão universal dos conhecimentos e das técnicas ocasionaria a libertação do homem, contribuindo para sua progressiva felicidade. Em 1780, quando Guyton de Morveau traduziu uma coleção de ensaios do químico sueco Torbern Bergman, este o persuadiu a rever a linguagem da química (cf. Donovan, 1996). Bergman foi aluno e amigo de Carl Lineu, que havia criado o sistema de classificação das plantas, tendo por base uma nomenclatura binomial, em que o primeiro nome designava o gênero e o segundo a espécie (cf. Carneiro, 2006).

Em 1786, Guyton de Morveau apresentou seu projeto inicial de revisão da nomenclatura a Lavoisier, Berthollet e Fourcroy. Estes se entusiasmaram com o projeto e durante as discussões sobre a nova nomenclatura Guyton de Morveau converteu-se à teoria antiflogístico de Lavoisier (cf. Poirier, 1998).

Lavoisier introduziu duas modificações importantes no projeto inicial de Guyton de Morveau: baseou as denominações na sua própria teoria (antiflogístico) e sublinhou que a nomenclatura deveria refletir a natureza. Lavoisier inspirou-se em Condillac: linguagem e conhecimento são indissociáveis e, por isso, refazer a linguagem é refazer a ciência. A Lógica de Condillac foi publicada em 1780 e fornecia os argumentos teóricos necessários à justificação das mudanças defendidas por Lavoisier. A nova nomenclatura proposta por Lavoisier e seus colaboradores tinha um conteúdo “ideológico", pois quem a aceitasse estaria consequentemente aceitando a teoria do oxigênio, unificadora dos fenômenos de oxidação, combustão, respiração e acidez. A nova nomenclatura foi apresentada em quatro sessões públicas na Academia Real de Ciências, entre abril e junho de $17^{8} 7$, sob a forma de memórias, que comporiam a obra Método de nomenclatura química (Méthode de nomenclature chimique) (cf. Guyton de Morveau et al., 1787). 
Segundo Guyton de Morveau, a nomenclatura sistemática proposta nesta obra foi formada, em grande parte, a partir de raízes gregas, e cada nome devia dar uma idéia das propriedades da substância designada.

a lógica da nomenclatura exigiu mesmo que ela fosse a primeira a ser nomeada, para que a palavra que nos lembra a ideia traga o tipo de denominações de seus compostos; nos satisfizemos estas condições adotando a expressão de oxigênio, tirando-a, como o senhor Lavoisier propôs há muito tempo, do grego ỏ ̌̌ s, ácido, e $\gamma \varepsilon \imath v v \alpha \imath$, gerar, devido à propriedade bem constante deste princípio, base do ar vital (...) (Guyton de Morveau et al., 1787, p. 32).

A determinação em estabelecer uma linguagem, cuja etimologia das palavras designa uma ideia, sugere a tese associativa que foi defendida por David Hartley (17051757) e Joseph Priestley (1733-1804), na qual as palavras deveriam estar associadas às ideias que expressavam.

Priestley foi a principal figura da química pneumática inglesa. Como a maioria dos educadores do século Xviıı, admirava John Locke e absorveu David Hartley. Hartley desenvolveu uma psicologia associativa, afirmando que todas as ideias complexas ou "intelectuais" surgem das simples, que, por sua vez, "surgem das impressões feitas por objetos externos sobre as várias partes de nossos corpos". Essas sensações, quando muitas vezes repetidas, dão origem a ideias. A associação era considerada a base da educação e da vida, uma forma sistemática de alcançar objetivos morais, intelectuais e religiosos. Priestley mostrou como o uso do associativismo seria a base do bom falar, do escrever e do ensino e, portanto, influenciaria a formação da imaginação, dos gostos e de todos os prazeres intelectuais (cf. Watts, 1994; Alexander, 2008).

Benjamin Franklin frequentava o salão de Lavoisier e tinha como amigos comuns Madame Lavoisier e David Hartley, filho do filósofo, com os quais trocava correspondência. Através dessas relações, podem ter circulado ideias e interesses comuns (cf. Sparks, 184, $)$.

Lavoisier, em sua Reflexões sobre a instrução pública (Réflexions sur l'instruction publique) (1893 [1793], p. 533), incluiu a "análise das sensações e das ideias" na parte dos estudos morais e políticos, tanto no terceiro grau a ser desenvolvido nos institutos, quanto no quarto grau de estudos a serem cursados nos Liceus, e faz também referência à tábula rasa de John Locke na introdução do texto (cf. Lavoisier, 1893 [1793], p. 516, 533).

O Método inclui também um novo sistema de caracteres químicos elaborado por Jean Henri Hassenfratz e Pierre August Adet (cf. Sánches \& Belmar, 2006). Estes autores criticavam o estado de confusão gerado pelos símbolos químicos até então usados, recomendando a utilização de caracteres químicos adequados para diferenciar subs- 
tâncias simples e compostas. Buscavam símbolos que representassem as substâncias formadoras dos compostos e que oferecessem uma indicação da proporção entre as quantidades presentes na composição. Representaram por uma linha reta as substâncias que se combinavam com várias outras, um triângulo para a terra e o álcalis, um semicírculo para as substâncias inflamáveis, um círculo para os metais, um quadrado para os radicais e um ponto para aquelas substâncias cuja composição ainda não era conhecida. Para diferenciar as substâncias de um mesmo grupo, propuseram a utilização das letras iniciais dos seus nomes em latim (cf. Crosland, 2004).

\section{O TRATAdo de LAVOisier}

Logo depois, Lavoisier publicou o Tratado elementar de química (Traité élémentaire de chimie) (cf. Lavoisier, 2007 [1789]), apresentando resultados experimentais obtidos no decorrer de vinte anos de trabalho em seu laboratório. O tratado utilizava a nova nomenclatura e dirigia-se a todos os iniciantes na química (cf. Fauque, 1995).

Foi principalmente do grego que tiramos as palavras novas e nós o fizemos de maneira que a sua etimologia lembrasse a idéia das coisas que nos propomos a indicar (Lavoisier, 2007 [1789], p. 51).

Demos à base da porção respirável do ar o nome de oxigênio, derivando-o de

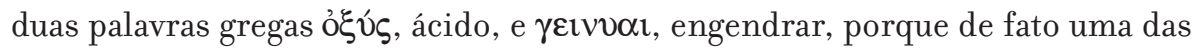
propriedades mais gerais dessa base é formar ácidos com a maior parte das substâncias (Lavoisier, 2007 [1789], p. 5).

No século xviıI, o modelo da química existente era mineral, e os compostos eram composições binárias de corpos simples. Os ácidos e bases eram óxidos de radicais e de metais e os sais, compostos de ácidos e bases. Lavoisier inovou e explicou satisfatoriamente o processo vital da respiração, levando a química de forma contundente para além do universo mineralógico (cf. Santos, 1998).

O Tratado elementar de química contém, na seção 3, a "tabela da nomenclatura química”, proposta por Morveau, Lavoisier, Bertholet e Fourcroy em maio de 1787 (cf. Lavoisier, 1805 [1789], p. 80-1). A tabela de substâncias é apresentada em seis colunas duplas, com os nomes novos e antigos de cada uma delas. A coluna I traz as cinquenta e cinco substâncias, "substâncias não decompostas", contendo oxigênio, azoto, hidrogênio, enxofre, fósforo, carbono, os radicais e os metais conhecidos. A coluna II, denominada "postos no estado de gás pelo calórico", apresenta o gás oxigênio, o gás azoto, o gás hidrogênio, hoje classificados como substâncias simples. As demais colunas 
receberam os respectivos nomes: "combinados com o oxigênio, oxigenados gasosos, oxigenados com bases, combinados sem serem levados ao estado de ácido". As substâncias numeradas de 05 (azoto) até 3o (radical bômbico) foram classificadas como substâncias acidificáveis. As substâncias, cujos números iam de 31 (arsênio) até 47 (ouro) foram classificadas como substâncias metálicas. Sílica, alumina, barita, cal e magnésia foram classificadas como terras e, potassa, soda e amoníaco como álcalis. Vale ressaltar que não foi apresentada nessa tabela nenhuma fórmula química como atualmente conhecemos.

Com a nova nomenclatura, o gás flogisticado ou mofeta atmosférica passa a ser denominado simplesmente gás azoto. O gás inflamável denomina-se gás hidrogênio. Os metais mantiveram os nomes de origem. A terra vidrificável ou quartzo recebeu o nome de sílica; a argila ou terra de alúmen, o nome de alumina. O oxigênio, ao combinar-se com a prata, forma o óxido de prata (antigo cal de prata). Ao combinar-se com o radical cítrico forma o ácido cítrico (antigo ácido do limão). Combinando-se com o radical láctico forma o ácido láctico (antigo ácido do soro do leite azedo), e assim por diante.

Lavoisier tentou expor a química de forma analítica, do simples para o complexo, com o objetivo de formar químicos no prazo aproximado de dois anos.

O Tratado serviu como modelo para o movimento intelectual, que propagava o espírito "analítico" e que pretendia tornar as ciências acessíveis à maioria das pessoas e úteis para todos, passando a fazer parte do discurso político como uma garantia de progresso (cf. Dhombres, 1996). Para Jean Dhombres (1996), o termo "elementar", introduzido no título da obra, era uma alusão aos Elementos de Euclides, e referiam-se mais ao rigor matemático da nova química que a sua acessibilidade.

O método analítico, devido a sua tendência à simplificação, trouxe como consequência a especialização. Cada ciência passou a ter sua própria linguagem, seus próprios métodos e objetivos.

A influência de Condillac foi explicitamente reconhecida por Lavoisier no Tratado elementar de química, tendo-o citado por diversas vezes, como, por exemplo,

só pensamos com a ajuda das palavras, pois as línguas são os verdadeiros métodos analíticos, e a álgebra é a mais simples, a mais exata e a mais bem adaptada ao seu objeto entre todas as maneiras de enunciar-se; ela é, a um só tempo, uma linguagem e um método analítico; enfim, a arte de raciocinar reduz-se a uma linguagem bem feita. (Condillac, apud Lavoisier, 2007 [1789], p. 17).

Mas enfim, as ciências progrediram porque os filósofos observaram melhor e puseram, na sua linguagem, a precisão e a exatidão que tinham posto nas suas observações; corrigiu-se a língua e raciocinou-se melhor (Condillac, apud Lavoisier, 2007 [1789], p. 25) 
Para Étienne Bonnot de Condillac (1973 [1780]), todos os nossos conhecimentos e nossas faculdades vêm das sensações que são nossas maneiras de ser. Ainquietude humana seria o primeiro principio, que produziria os hábitos de tatear, ver, escutar, sentir, degustar etc. A memória seria a sensação transformada.

Quando as sensações são adquiridas pelo método analítico, elas se dispõem de forma organizada no espírito. "Para falar de uma maneira compreensível, é preciso conceber e exprimir ideias em uma ordem analítica que decompõe e recompõe cada pensamento" (Condillac, 1973 [1780], p. 79). Somente pela análise deve ser feita a instrução, e a condução deve ser feita do conhecido para o desconhecido.

Desde que as línguas tornaram-se métodos analíticos, pensamos segundo os hábitos que provêm delas. As línguas das ciências possuem os mesmos defeitos que as outras, "mas as ciências fizeram progressos, porque os filósofos observaram melhor e colocaram em sua linguagem a precisão e a exatidão que haviam colocado em suas observações" (Condillac, $197^{3}$ [1780], p. 117). A análise só nos ensinará a raciocinar na medida em que nos ensinar a determinar as ideias abstratas e gerais e a fazer bem a nossa língua. A arte de raciocinar só se reduz a uma língua bem feita porque a organização das nossas ideias está subordinada aos nomes dos gêneros e espécies.

A simplicidade das expressões facilita o raciocínio e a análise utiliza uma língua mais simples. Enfim, as línguas são métodos analíticos, o raciocínio só se aperfeiçoa se as línguas se aperfeiçoarem, e a arte de raciocinar, cujo exercício depende do uso das palavras, só pode ser exercida através de uma língua bem feita que contenha os meios que permitam as análises. A álgebra é um método analítico e é uma língua, prova decisiva de que os progressos das ciências dependem dos progressos das línguas.

A nova nomenclatura química foi entendida como uma ofensiva contra o flogisto e desencadeou uma forte controvérsia. A linguagem da academia diferia, em grande parte, da linguagem utilizada pelos artesãos e pelos droguistas. Além disso, os artesãos farmacêuticos viam na nova nomenclatura uma manobra com o objetivo de criar uma dependência dos artesãos com respeito aos acadêmicos (cf. Abrantes, 2006).

\section{A Difusão DA NOVA NOMENGLATURA QUÍMICA}

Após vinte anos, a nomenclatura foi praticamente adotada por toda a Europa. Vicente Seabra Telles, brasileiro que estudava em Portugal, usou pioneiramente a nova nomenclatura química em seu livro Dissertação sobre a fermentação, publicado em $177_{7}^{8}$, e predominantemente no segundo volume do Elementos de chimica, publicado em 1790 (cf. Filgueiras, 2007). Em 1801, Seabra publicou a Nomenclatura chimica portugueza, franceza 
e latina, que traz uma completa adaptação da nomenclatura química às regras da língua portuguesa (cf. Amorim da Costa, 1995).

Para obter um tal êxito na adoção da nova nomenclatura, Lavoisier e seus colaboradores empenharam-se em uma campanha de persuasão. O periódico Annales de Chimie et de Physique tornou-se um veículo importante para esse fim, evidenciando os pontos fracos da teoria do flogisto e realçando as vantagens da nova teoria, convencendo os químicos a utilizarem a nova nomenclatura (cf. Santos, 1998).

Como uma estratégia de Lavoisier para consolidar a sua própria teoria e derrubar a teoria do flogisto, Madame Lavoisier traduziu, em 1788, para a língua francesa, o livro An essay on phlogiston and the constitution of acids, do irlandês Richard Kirwan (cf. Kirwan, 1788). A obra traduzida continha notas de Lavoisier e de seus colaboradores, refutando as idéias de Kirwan. Travou-se uma batalha intelectual e Kirwan, em meio do exercício de argumentar contra os teóricos do oxigênio, conseguiu perceber, em 1791, que o sistema de explicações oferecido pela teoria do oxigênio era mais coerente do que aquele oferecido pela perspectiva que ele inicialmente defendia, e assim converteu-se à teoria do oxigênio (cf. Thagard, 2007 [1990]).

Apesar de a França, na época de Lavoisier, possuir cerca de 5०\% de analfabetos, em Paris, cidade onde residia, a maioria das pessoas era alfabetizada. A existência da imprensa (prensa tipográfica), que agilizava a impressão das obras, contribuiu para acelerar a difusão das idéias iluministas, pois era também moda entre os parisienses ler os autores iluministas e os feitos das ciências. O fato de Lavoisier publicar em francês (costumava-se publicar em latim), dando oportunidade de acesso a uma maior camada da população, também contribuiu para a eficaz divulgação de seu trabalho.

O mérito da nomenclatura que adotamos consiste principalmente em que a substância simples, uma vez nomeada, faz com que o nome de todos os seus compostos decorra necessariamente dessa primeira palavra (Lavoisier, 2007 [1789], p. 52).

No recorte anterior observa-se a nítida influência de John Locke, que afirmava que "(...) a função das palavras é serem marcas sensíveis das ideias, e as ideias que elas representam constituem a sua significação própria e imediata" (Locke, 1999 [1689], p. 545). Para Locke, além da imperfeição que é natural na linguagem, há várias faltas causadas pelos próprios homens, como a que consiste em usar palavras que não nos fazem ligar idéias claras e distintas. Sabendo que, para Locke,

aquele que aplica os nomes a idéias diferentes das do uso comum carece de propriedade na sua linguagem e fala estropiadamente. E aquele cujas idéias das 
substâncias são incompatíveis com a existência real das coisas carece do mateial do verdadeiro conhecimento e tem, em vez disso, quimeras (1999 [1689], p. 690).

Lavoisier devota toda uma preocupação com essa abordagem da linguagem mencionada anteriormente, conforme a sua própria justificativa na obra.

Não julgamos que nos fosse permitido mudar nomes recebidos e consagrados na sociedade por um antigo uso. Portanto, demos às palavras água e gelo os seus significados vulgares; do mesmo modo, exprimimos por ar a coleção dos fluidos elásticos que compõem a nossa atmosfera; mas não nos acreditamos obrigados a esse respeito a manter denominações mais modernas recentemente propostas pelos físicos (Lavoisier, 2007 [1789], p. 51).

Lavoisier incorporou varias ideias de John Locke, mas felizmente não as seguiu cegamente, pois do contrário talvez não tivesse elevado a química à categoria de ciência e contribuído para sua plena institucionalização (cf. Maar, 2004), uma vez que, para Locke,

essa maneira de adquirir e aumentar o nosso conhecimento acerca das substâncias só pela experiência e história, que é tudo quanto a fraqueza das nossas faculdades, neste estado de mediocridade em que estamos neste mundo, pode atingir, fazme suspeitar que a filosofia natural não é susceptível de transformar-se em ciência (Locke, 1999 [1689], p. 895).

Para Locke, a lógica (doutrina dos sinais) era uma ciência cujo assunto consistiria em considerar a natureza dos sinais de que o espírito faz uso para a compreensão das coisas, ou para comunicar os seus conhecimentos aos outros. Ora, dado que as coisas são as ideias e um homem não pode enxergar a cena das ideias de outro, para comunicar os nossos pensamentos uns aos outros, bem como para registrá-los são necessários os sinais das nossas idéias, os sons articulados, as palavras.

\section{Considerações Finais}

Lavoisier e seus colaboradores sistematizaram uma nova nomenclatura química com base nos pensamentos linguísticos de Condillac e tendo como inspiração John Locke e os ideais iluministas. Obtiveram êxito na implantação da nova nomenclatura química no mundo ocidental e, em acréscimo, conseguiram a derrocada da teoria do flogisto. 
Se, por um lado, encontramos vários indícios que reforçam a tese de Thomas Kuhn (2009 [1962]) de que Lavoisier consolidou uma revolução química, impondo uma descontinuidade no desenvolvimento científico, por outro lado, encontramos também indícios que reforçam a tese de pequenas mutações no desenvolvimento científico, reforçando um progresso contínuo, tal como apregoado por Ludwik Fleck (2010 [1935]).

Na construção da nova nomenclatura química, Lavoisier preocupou-se em utilizar os termos já consolidados pela comunidade científica da época, mas introduziu novos termos, e a forma como esses termos foram articulados implicava na aceitação da sua teoria do oxigênio, que despontava como um novo paradigma. De acordo com Kuhn (2009 [1962]), quando ocorre a transição de uma teoria para a seguinte, os significados ou condições de aplicabilidade das palavras mudam sutilmente, e ele denomina teorias sucessivas como incomensuráveis, mas não incomparáveis. Novos paradigmas nascem dos antigos, incorporam comumente grande parte do vocabulário e dos aparatos, tanto conceituais como experimentais, que o paradigma tradicional já empregava. Mas raramente utilizam esses elementos emprestados de uma maneira tradicional (cf. Kuhn, 2009 [1962], p. 190-1).

Para Kuhn (2006), cada nova especialidade desenvolve seu próprio léxico, sua própria linguagem, e a comunidade que compartilha esse léxico estrutura-se com suas próprias normas e critérios, mas, no caso de Lavoisier, não creio que possamos denominar a sua química como uma especialidade, pois o eixo principal da ciência química ainda estava em formação. A meu ver, detecta-se uma mutação no estilo de pensamento, oriundo da comunicação intercoletiva de ideias. De acordo com Fleck (2010 [1935]), um estilo de pensamento contém vestígios históricos, desenvolvimento evolucionário de vários elementos de outro estilo. Percebemos a formação de uma comunidade científica compartilhando a mesma linguagem química, a crença na teoria do oxigênio e guiando-se pelas suas próprias normas. A consolidação dessa comunidade levou cerca de vinte anos, obtida com muita luta e um trabalho contínuo de persuasão. A preocupação de Lavoisier com a comunicação de suas idéias era evidente; imbuído do espírito iluminista, consolidou obras que possibilitaram a circulação das ideias de um círculo esotérico para o exotérico. Lavoisier viveu intensamente o processo de consolidação de suas ideias e o ápice do seu paradigma, mas não viveu o suficiente para ele próprio deparar-se com os momentos de crise que certamente iriam aparecer, colocando em xeque o seu estilo de pensamento.e

Regina Simplício Carvalho Professora Doutora do Departamento de Química, Universidade Federal de Viçosa, Brasil. resicar@ufv.br 


\begin{abstract}
Lavoisier's chemical nomenclature was systematized based on the Logic of Condillac, and both authors were inspired by John Locke. Lavoisier persistently attacked the phlogiston theory until its demise, and he succeeded in getting the support of several scientists to his oxygen theory. The use of the new chemical nomenclature implied acceptance of that theory. He wrote several works, including Methode de nomenclature chimique and Traité élémentaire de chimie, which spread the new chemical nomenclature throughout Europe. Assuming that science is a cultural product, we present a discussion in light of the works of Ludwik Fleck and Thomas Kuhn.
\end{abstract}

KEYwords $\bullet$ Lavoisier. Chemical nomenclature. Oxygen theory. Language. Kuhn. Fleck.

\title{
REFERÊNGIAS BIBLIOGRÁFICAS
}

Abrantes, P. C. G. Imagens de natureza, de ciência, e educação: o caso da Revolução Francesa. In: Stein, S.\& Kuiava, E. (Org.). Linguagem, ciência e valores: sobre as representações humanas do mundo. Caxias do Sul: Educs, 2006. p. 11-58.

Alexander, R. The language of the "naked facts": Joseph Priestley and the apocalypse of language. Language \& Communication, 28, 1, p. 21-35, 2008.

Amorim da Costa, A. M. Lavoisier's chemical nomenclature in Portugal. In: Bensaude-Vincent, B. \& Abbri, F. (Ed.). Lavoisier in European context: negotiating a new language for chemistry. New York: Watson Publications, 1995. p. 155-71.

Bensaude-Vincent, B. \& Abbri, F. (Ed.). Lavoisier in European context: negotiating a new language for chemistry. New York: Watson Publications, 1995.

Bensaude-Vincent, B. \& Stengers, I. Histoire de la chimie. Paris: La Découverte, 2001.

Carneiro, A. Elementos da história da química do século xviri. Boletim da sociedade Portuguesa de Quími$c a, 102$, p. 25-31, 2006.

Condé, M. L. L. (Org.). Ciência e cultura na história. Belo Horizonte: Argumentum, 2006.

Condillac, E. B. de. Lógica ou os primeiros desenvolvimentos da arte de pensar. In: Condillac, Helvétius, Degérando: textos escolhidos. Tradução N. A. Aguilar. São Paulo: Abril, $197^{3}$ [178o]. p. 67-14.0. (Os Pensadores, 27)

Crosland, M. P. Historical studies in the language of chemistry. New York: Dover / Phoenix Editions, 2004.

Darnton, R. \& Roche, D. (Org.). A imprensa na França, 1775-180o. São Paulo: Edusp, 1996.

Dhомвres, J. Livros dando nova forma à ciência. In: Darnton, R. \& Roche, D. (Org.). A imprensa na França, 1775-1800. São Paulo: Edusp, 1996. p. 239-85.

Donovan, A. Antoine Lavoisier: science, administration, and revolution. Oxford: Blackwell, 1996.

Faudue, D. O papel iniciador de Lavoisier. Química Nova, 18, 6, p. 567- 73, 1995.

Filgueiras, C. A. L. Lavoisier: o estabelecimento da química moderna. $2^{\mathrm{a}}$ ed. São Paulo: Odysseus, 2007.

FLECK, L. Gênese e desenvolvimento de um fato científico. Belo Horizonte: Fabrefactum, 2010 [1935].

Fontes da Costa, P. Simbologia e alegoria na linguagem alquímica. Boletim da Sociedade Portuguesa de Química, out.-dez., p. 29-35, 2002. Disponível em: <http://www.spq.pt/boletim/docs/BoletimSPQ_ ०87_029_08.pdf>. Acesso em: 20 jul. 2010.

Guyton de Morveau, L. B.; Lavoisier, A. L.; Berthollet, C. L.; Fourcroy, A. F.; Hassenfratz, J. H. \& Adet, P. A. Méthode de nomenclature chimique. Paris: Cuchet Libraire, 1787. Disponível em: <http:// books.google.com.br>. Acesso em: 02 nov. 2010.

Holmyard, E. J.Alchemy. New York: Dover, 1990. 
Kinwan, R. Essai surle phlogistique et surla constitution des acides. Tradução M. A. P. Lavoisier. Paris: Rue et Hôtel Serpente, 1788.

Kunn, T. S. $O$ caminho desde a estrutura. São Paulo: Editora Unesp, 2006. A estrutura das revoluções científicas. 9 ed. São Paulo: Perspectiva, 2009 [1962].

Lavoisier, A. L. Traité élémentaire de chinie. Paris: Chez les Libraires Associés, 1805 [1789]. Réflexions surl'instruction publique. Paris: Imprimerie Du Pont, 1893 [1793]. Tratado elementar de química. Tradução L. S. P. Trindade. São Paulo: Madras, 2007 [1789].

Locke, J. Ensaio sobre o entendimento humano. Lisboa: Fundação Calouste Gulbenkian, 1999 [1689].

MaAr, J. H. Pequena história da química. Primeira parte: dos primórdios a Lavoisier. Florianopólis: PapaLivro, 1999.

. Aspectos históricos do ensino superior de química. Scientia Studia, 2, 1, p. 33-84, 2004.

Moran, B. T. Alchemy, chemistry and the history of science. Studies in History and Philosophy of Science A,

31,4, p. 711-20, 2000.

Poirier, J.-P. Lavoisier: chemist, biologist, economist. Tradução R. Balinski. Philadelphia: University of Pennsylvania Press, 1998.

Sanches, J. R. \& Belmar, A. G. La revolución química: entre la historia y la memória. Valência: PUV, 2006.

SAntos, A. M. N. Radiografia da química do século xvııI: triunfo e sedimentação de uma área científica. Colóquio Ciências: Revista de Cultura Científica, 21, p. 53-76, Lisboa, 1998.

Shapin, S. \& Schaffer, S. El Leviathan y la bomba de vacío: Hobbes, Boyle y la vida experimental. Buenos Aires: Universidad Nacional de Quilmes, 2005.

Sparks, J. (Ed.). The works of Benjamin Franklin. Philadelphia: Childs \& Peterson, 184, O. v. 10.

Stein, S.\& KuIAVA, E. (Org.). Linguagem, ciência e valores: sobre as representações humanas do mundo. Caxias do Sul: EDUCS, 2006.

Thagard, P. A estrutura conceitual da revolução química. Tradução M. R. da Silva e M. Giro. Princípios, 14,22, p. 265-303, 2007 [1990].

Watrs, R. Joseph Priestley (1733-1804). Prospects: the quarterly review of comparative education, 24, 1/2, p. $34,3-5^{3}, 1994$. 